\title{
On the Linkage between AMPA and NMDA Receptor-mediated EPSPs in Homosynaptic Long-Term Depression in the Hippocampal CA1 Region of Young Rats
}

\author{
Min-Yi Xiao, ${ }^{1}$ Martin Karpefors, ${ }^{1}$ Bengt Gustafsson, ${ }^{2}$ and Holger Wigström ${ }^{1}$ \\ Departments of 'Medical Biophysics and 'Physiology, Göteborg University, Göteborg, Sweden
}

Homosynaptic long-term depression (LTD) was studied in hippocampal slices from 12-18-d-old rats using field EPSP recording in the apical dendritic layer of CA1 pyramidal cells. Independent estimates of the $\alpha$-amino-3-hydroxy-5methylisoxazolepropionic acid (AMPA) and the $N$-methyl-Daspartic acid (NMDA) receptor-mediated components of the field EPSP were obtained in parallel using early and late measurements of a dual-component EPSP in a low-magnesium solution. LTD was induced by low-frequency stimulation (LFS; $2 \mathrm{~Hz}$ for $10 \mathrm{~min}$ ), resulting in equal relative changes of the AMPA and NMDA receptor-mediated components. Under conditions when the AMPA receptor-mediated component was fully blocked, a similarly sized LTD was observed for the pure NMDA receptor-mediated EPSP (measured as initial slope or peak amplitude). Equal changes in AMPA and NMDA receptor-mediated components occurred also upon application of the adenosine agonist $\mathrm{N}^{6}$-cyclohexyladenosine (CHA), known to act by decreasing transmitter release. On the other hand, LTD was found to interact in a multiplicative manner with the presynaptic release changes induced by $\mathrm{CHA}$ and by pairedpulse facilitation. The induction of the LTDs of both AMPA and NMDA receptor-mediated EPSPs was blocked by the NMDA receptor antagonist $\mathrm{D}(-)$-2-amino-5-phosphonopentanoic acid and by the phosphatase inhibitor okadaic acid. Partial blockade of LTD by okadaic acid resulted in equal partial blockade of the LTDs of the AMPA and NMDA receptor-mediated components. On the other hand, the L-type calcium channel blocker nifedipine, the metabotropic glutamate receptor antagonist (RS)- $\alpha$-methyl-4-carboxyphenylglycine, the nitric oxide synthase inhibitor Nw-nitroL-arginine, and the heme oxygenase inhibitor protoporphyrin IX zinc(II) had no effect on LTD of either the AMPA or the NMDA receptor-mediated component.

These results of equal changes of AMPA and NMDA receptor-mediated components of the field EPSP in association with LTD, and the consistent parallelism of effects or noneffects on these components by various receptor antagonists and enzyme inhibitors, seem more easily ex-

\footnotetext{
Received Dec. 6. 1994; revised Jan. 17. 1995; accepted Jan. 24, 1995

This work was supported by the Swedish Medical Research Council (Projects 05954 and 05180$)$ and the foundations of Magn. Bergvall and Ake Wiberg.

Correspondence should be addressed to Holger Wigström, Department of Medical Biophysics, Goteborg University. Medicinaregatan 11, S-41390 Goteborg, Sweden.

Copyright 1995 Society for Neuroscience $0270-6474 / 95 / 154496-11 \$ 05.00 / 0$
}

plained by a presynaptic locus for LTD than by a postsynaptic one.

[Key words: synaptic plasticity, long-term depression, AMPA receptors, NMDA receptors, hippocampus, CA1 area]

An important feature of many central synapses is their ability to undergo long-lasting changes upon usage. For instance, following certain patterns of afferent activation, glutamatergic synapses in the hippocampus and neocortex can, in the long-term, increase as well as decrease their efficacy. These processes, referred to as long-term potentiation (LTP) and long-term depression (LTD), respectively, have attracted much attention due to their possible involvement in learning and memory (Artola and Singer, 1993; Bliss and Collingridge, 1993; Linden, 1994). Both homosynaptically induced LTP and LTD found in the hippocampal CAl area are now fairly well understood at the induction level. They are both believed to be initiated by an influx of calcium ions through postsynaptic $N$-methyl-D-aspartate (NMDA) receptor channels, possibly depending on the quantitative and temporal aspects of the calcium influx, and different enzymatic systems are triggered, leading to either an up- or downregulation of a common synaptic modification (Dudek and Bear, 1992; Mulkey and Malenka, 1992).

Relatively little is currently known about the linkage between the rise in postsynaptic calcium and the persistent synaptic modification as well as the nature and location of the latter. In attempts to decide the location of LTP/LTD, advantage can been taken of the fact that the glutamate-evoked EPSP consists of two components, mediated via $\alpha$-amino-3-hydroxy-5-methylisoxazolepropionic acid (AMPA) and NMDA receptor channels, respectively (Wigström and Gustafsson, 1986; Collingridge et al.. 1988; Hestrin et al., 1990). For instance, results that LTP/LTD is associated with equal changes in AMPA and NMDA receptor-mediated EPSPs, or with an increase of the AMPA receptormediated EPSP only, would argue respectively for or against a presynaptic location of the synaptic modification. Studies of changes in AMPA and NMDA receptor-mediated components during LTP have, however, given conflicting results. Whereas some studies report that LTP is essentially associated only with a change in the AMPA receptor-mediated component (Kauer et al., 1988; Muller and Lynch, 1988; Perkel and Nicoll, 1993), others have reported a substantial parallel LTP of the NMDA receptor-mediated EPSP, either relatively smaller than the AMPA receptor-mediated one (Asztely et al., 1992) or equal to it (Clark and Collingridge, 1994). LTD, on the other hand, was recently found to be associated with near equal changes of the 
AMPA and NMDA receptor-mediated components of the field EPSP (Xiao et al., 1994).

In view of the divergent results on LTP regarding the relative contribution of the two receptor types, one may ask to what extent the finding of near equal changes of AMPA and NMDA receptor-mediated components in LTD was merely fortuitous. To explore this question, the present study has examined the robustness of the coupling between the LTDs of the AMPA and NMDA receptor-mediated field EPSPS by applying various pharmacological treatments that might be expected to interfere with LTD. Moreover, the possibility that the changes in AMPA and NMDA receptor-mediated field EPSPs observed during LTD reflect a presynaptic modification has been explored by comparing these changes with those given by procedures known to affect presynaptic function.

\section{Materials and Methods}

Slice preparation and electrophysiology. Experiments were performed on Sprague-Dawley rats from 48 rats, $12-18 \mathrm{~d}$ old, an age at which LTD can be readily induced (Dudek and Bear, 1993). After decapitation, the hippocampus was dissected out and transverse slices, $400 \mu \mathrm{m}$ thick, were cut with a tissue chopper. The slices were transferred to a constantflow recording chamber (Brain Slice Chamber, Medical Systems Corp., Greenvale, NY), where they were maintained at $29-30^{\circ} \mathrm{C}$ in the interface hetween an oxygenated $\left(95 \% \mathrm{O}_{2}, 5 \% \mathrm{CO}\right)$ salt solution and humidified gas $\left(95 \% \mathrm{O}_{2}, 5 \% \mathrm{CO}_{2}\right)$. The solution contained (in $\left.\mathrm{mM}\right) \mathrm{NaCl}$, $119 ; \mathrm{KCl}, 2.5 ; \mathrm{CaCl}_{2}, 2 ; \mathrm{MgCl}_{2}, 0.1 ; \mathrm{NaHCO}_{3}, 26 ; \mathrm{NaH}_{2} \mathrm{PO}_{4}, 1$; and glucose, 10 . In addition, I $\mu \mathrm{M}$ 6-cyano-7-nitroquinoxalline-2,3-dione (CNQX) was normally present to reduce the AMPA receptor-mediated component of the field EPSP. When a pure NMDA receptor-mediated field EPSP was used, the concentration of CNQX was raised to $10 \mu \mathrm{m}$ to fully block the AMPA receptor-mediated EPSP. A surgical cut was always made between $\mathrm{CA} 3$ and $\mathrm{CA} 1$ regions to prevent epileptiform bursting.

Extracellular responses were recorded in the apical dendritic layer of CA1 pyramidal cells, using glass micropipettes filled with $3 \mathrm{M} \mathrm{NaCl}$ (resistance, 1.5-4-M $\Omega$ ). Activation of two nonoverlapping synaptic populations was provided by placing two stimulating electrodes in the dendritic layer on either side of the recording electrode (Wigström and Gustafsson, 1985). Electrolytically sharpened tungsten wires were used as stimulating electrodes. Test stimuli consisted of $0.1 \mathrm{msec}$ negative constant-current pulses $(10-40 \mu \mathrm{A})$ delivered alternately at a frequency of $0.1 \mathrm{~Hz}$, the stimuli being kept $5 \mathrm{sec}$ apart. To induce LTD, one of the two electrodes was stimulated at a frequency of $2 \mathrm{~Hz}$ for $10 \mathrm{~min}$ (low-frequency stimulation, LFS). During this time, no stimulation was given to the other electrode.

Temporal separation between AMPA and NMDA receptor-mediated components of the field EPSP. In a previous study using adult guinea pigs (Asztely et al., 1992), the AMPA and NMDA receptor-mediated components of the field EPSP were measured independently, and in parallel, using an early and a late measurement of the composite field EPSP in a low-magnesium solution. To determine whether this method could be applied in the present study using young rats. the temporal characteristics of the two components were first examined

Bath application of the NMDA receptor antagonist $D(-)-2$-amino-5phosphonopentanoic acid (AP5; $25-50 \mu \mathrm{M}$ ) blocked a late portion of the field EPSP, leaving an early phase largely unaffected (Fig. 1Al) Conversely, bath application of the AMPA receptor antagonist CNQX $(10 \mu \mathrm{M})$ blocked an early portion of the field EPSP, leaving the late phase largely unaffected (Fig. 1A2). The potential remaining in the presence of both glutamate receptor antagonists (Fig. 1A2) was unaffected by drop application of $\mathrm{N}^{\circ}$-cyclohexyladenosine (CHA; $200 \mu \mathrm{M}$; an adenosine agonist that reduces transmitter release) (not shown). This potential, thus containing the stimulus artifact and the presynaptic volley, is referred to, in the following, as the nonsynaptic potential.

On the basis of the above decomposition experiment (Fig. 1AI,A2), the AMPA receptor-mediated field EPSP was estimated from the initial slope of the composite field EPSP, this value calculated as the slope of a regression line through the first $0.75 \mathrm{msec}$ of the field EPSP curve following the presynaptic volley (solid arrows in Fig. $1 A I$ ). The NMDA receptor-mediated field EPSP was estimated as a late amplitude of the composite field EPSP, this value calculated as the difference between

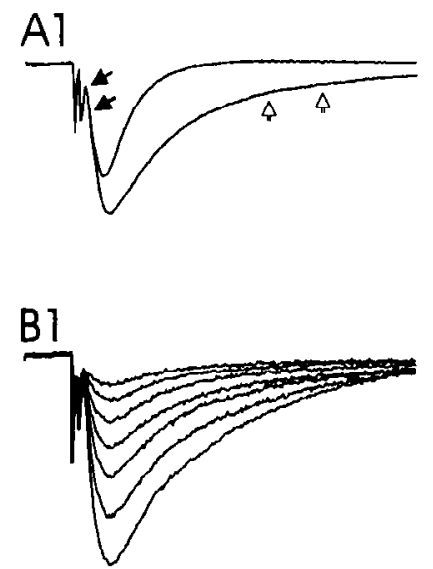

A2
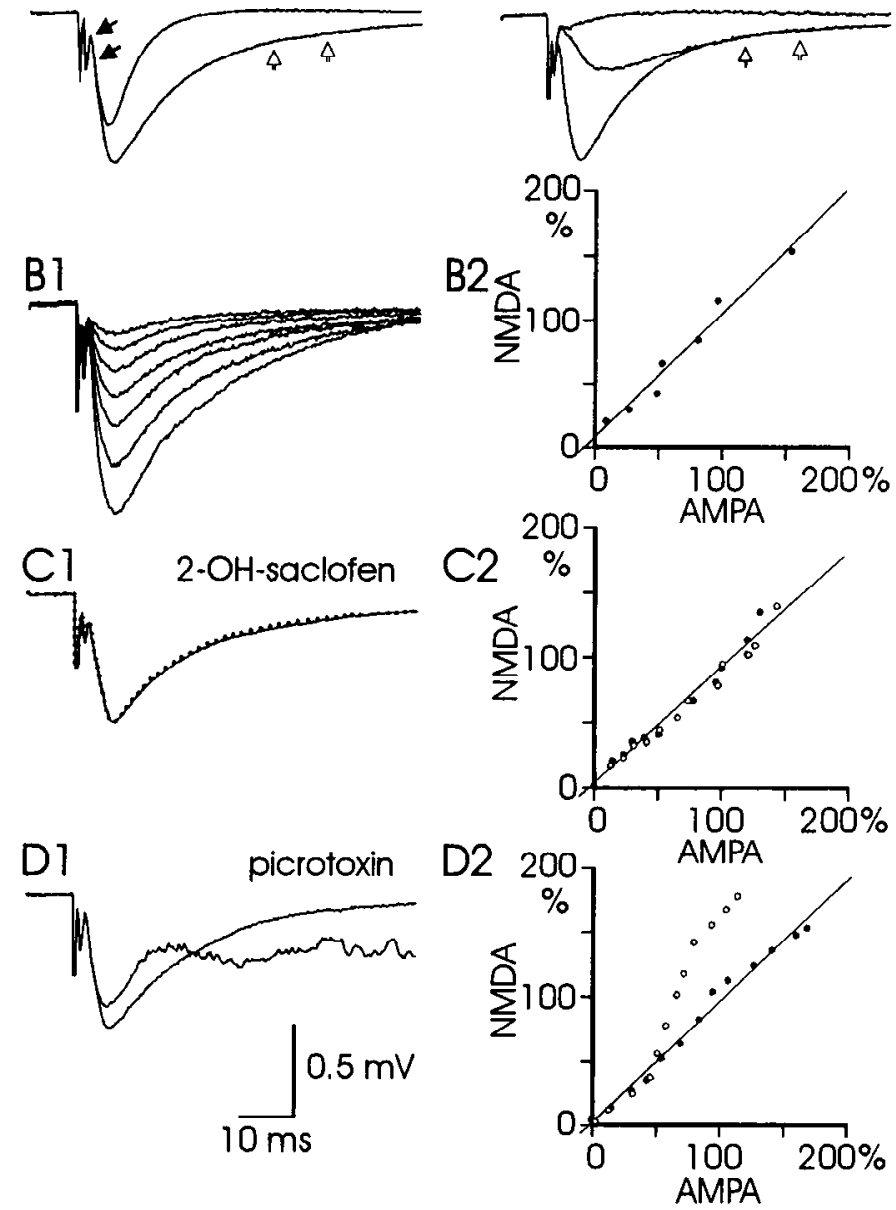

Figure 1. Use of early and late measurements of the field EPSP to estimate AMPA and NMDA receptor-mediated components. A/, Superimposed averaged records of the field EPSPs $(n=20)$ before and after bath application of the NMDA receptor antagonist AP5 $(50 \mu \mathrm{M})$. The application selectively blocked a late portion of the field EPSP. A2. Superimposed averaged records of the field EPSPs before and after bath application of the AMPA receptor antagonist CNQX $(10 \mu \mathrm{M})$, and the nonsynaptic field response remaining after additional application of AP5 $(50 \mu \mathrm{M})$. The application of CNQX selectively blocked an early portion of the field EPSP. Measurements of the initial slope (solid arrows in $A 1$ ) and the late amplitude (open arrows in $11, A 2$ ) of the ficld EPSP were used to obtain parallel estimates of AMPA and NMDA receptormediated components of the field EPSP (Materials and Methods). $B$, Field EPSPs recorded for a range of stimulus strengths ( $B I$; each curve is an average of 10 records) and the corresponding relation between the AMPA and NMDA receptor-mediated components (B2: the points are fitted by a linear regression line). The field EPSP size of $100 \%$ represents a typical size of the "baseline EPSP." $C$, Blockade of $\mathrm{GABA}_{\mathrm{B}}$ receptor-mediated inhibition had no effect on the recorded field EPSP. Averaged records taken before (solid) and after (dotted) bath application of the $\mathrm{GABA}_{B}$ receptor antagonist 2-OH-saclofen $(200 \mu \mathrm{M})$ are shown superimposed in $\mathrm{Cl} . \mathrm{C2}$ shows nearly identical linear relations before (solid circles and the regression line) and after drug application (open circles). D, Blockade of $\mathrm{GABA}_{\wedge}$ receptor-mediated inhibition leads to activation of voltage-dependent conductances. Averaged records taken before and after bath application of the $G_{A B A}$ receptor antagonist picrotoxin $(100 \mu \mathrm{M})$ are shown superimposed in $\mathrm{Dl}$. The volley and initial part of the EPSP are not changed by picrotoxin but the later part of the EPSP shows irregular waves that suggest activation of voltage-dependent conductances. The diagram in $D 2$ shows a linear relation between AMPA and NMDA measurements before picrotoxin application (solid circles and the regression line) but a nonlinear one after application of the drug (open circles). The datal suggest that the NMDA receptor-mediated component is not reliably measured by means of the "late amplitude" under conditions when GABA receptor-mediated inhibition is blocked, except at low stimulus strengths. 
the mean value during $10 \mathrm{msce}$ just preceding the stimulation and the mean value during $40 \pm 5 \mathrm{msec}$ following the stimulus artifact (open arrows in Fig. $1 A I, A 2$ ). In terms of the measures so defined, application of AP5 affected largely the late amplitude measurement, reducing it to $3.9 \pm 2.3 \%$ of control, whereas $84.7 \pm 3.1 \%$ of the initial slope remained $(n=10)$. Similarly, application of CNQX affected largely the initial slope. reducing it to $7.4 \pm 4.9 \%$ of control, whereas $94.2 \pm$ $2.8 \%(n=10)$ of late amplitude remained.

Validity of method for parallel measurements of AMPA and NMDA receptor-mediated field EPSP components. When the AMPA receptormediated component of the field EPSP was removed by CNQX application, the NMDA receptor-mediated EPSP would be subjected to less influence from membrane voltage. The small effect of CNQX on the late amplitude measurement, described above, suggests that such an influence is quite small under the present experimental conditions. To test this notion further, field EPSPs were recorded at a range of stimulus strengths (Fig. $\mid B /$ ). As shown in Figure $1 B 2$ for one experiment, the initial slope (AMPA) and late amplitude (NMDA) measurements increased in parallel, as expected from a minor influence of membrane voltage on the NMDA receptor-mediated component. This linear relation between the two measures was observed in all eight slices tested in this manner.

The application of CNQX might also be expected to reduce activation of inhibitory interneurons, and therefore reduce any influence of inhibitory synaptic currents on the recorded field potential. The small effect of CNQX application on the late amplitude measurement might then also be taken to indicate that this influence is rather minimal under the present experimental conditions. Nevertheless, to examine this issue in grcatcr detail, experiments were carried out in the presence of the appropriate antagonists.

Application of the GABA $\mathrm{B}_{\mathrm{B}}$ antagonist 2-OH-saclofen $(200 \mu \mathrm{M})$ had no effect on the field potential (Fig. 1Cl), and, as shown in one experiment in Figure $1 \mathrm{C2}$, the relation between the initial slope (AMPA) and late amplitude (NMDA) remained linear for a range of stimulus strengths $(n=5)$. On the other hand, application of the GABA antagonist picrotoxin $(100 \mu \mathrm{M})$ led to a more complex situation $(n=4)$. At low stimulation strengths (Fig. 1D2), the two EPSP measures increased in parallel. However, at higher strengths the later portion of the potential drastically changed character, showing multiple irregular peaks (Fig. $1 D I)$. This behavior suggests the involvement of voltage-dependent regenerative processes, making the late amplitude useless as a measure of NMDA receptor-mediated current. In view of these results, the experiments were carried out without application of $G \wedge B \wedge$ receptor antagonists, that is, with intact inhibition

Data analysis. The signals were amplified and filtered at $3 \mathrm{kHz}$ on an Axoclamp-2A (Axon Instruments), A/D converted, and led to a Nord-10/S microcomputer, which provided on-line measurement and display of field EPSP components. Data were then transferred to a PCclone personal computer for a more detailed off-line analysis. The changes in EPSP components during LTD were quantified as mean \pm SEM of responses taken 15-20 min after the end of the LFS, unless otherwise indicated. The values were normalized by division with the control level (mean response for a 5-10 min period immediately preceding the LFS)

Drugs. D(-)-2-Amino-5-phosphonopentanoic acid (AP5), 6-cyano-7nitroquinoxaline-2,3-dione (CNQX), 2-OH-saclofen, and (RS)- $\alpha$-methyl4-carboxyphenylglycine (MCPG) were obtained from Tocris Neuramin, UK; $\mathrm{N}^{*}$-cyclohexyladenosine (CHA), nifedipine, $\mathrm{N} \omega$-nitro-l-arginine (NOArg), and picrotoxin were from Sigma Chemical Company; okadaic acid was from Research Biochemicals Inc.; protoporphyrin IX zinc(II) (ZnPP) was from Aldrich Chemical Company.

\section{Results}

\section{LTD using a dual-component field EPSP}

$L T D$ of the AMPA receptor-mediated component. To obtain separate and parallel measurements of the AMPA and NMDA receptor-mediated components of the field EPSP, experinents were performed in a perfusion solution containing $0.1 \mathrm{mM}$ magnesium and $1 \mu \mathrm{M}$ CNQX (see Materials and Methods). In agreement with previous studies of LTD using entirely AMPA receptor-mediated EPSPs (Dudek and Bear, 1992, 1993; Mulkey and Malenka, 1992), application of a low-frequency stimulation (LFS: $2 \mathrm{~Hz}$ for $10 \mathrm{~min}$ ) using a composite field EPSP resulted
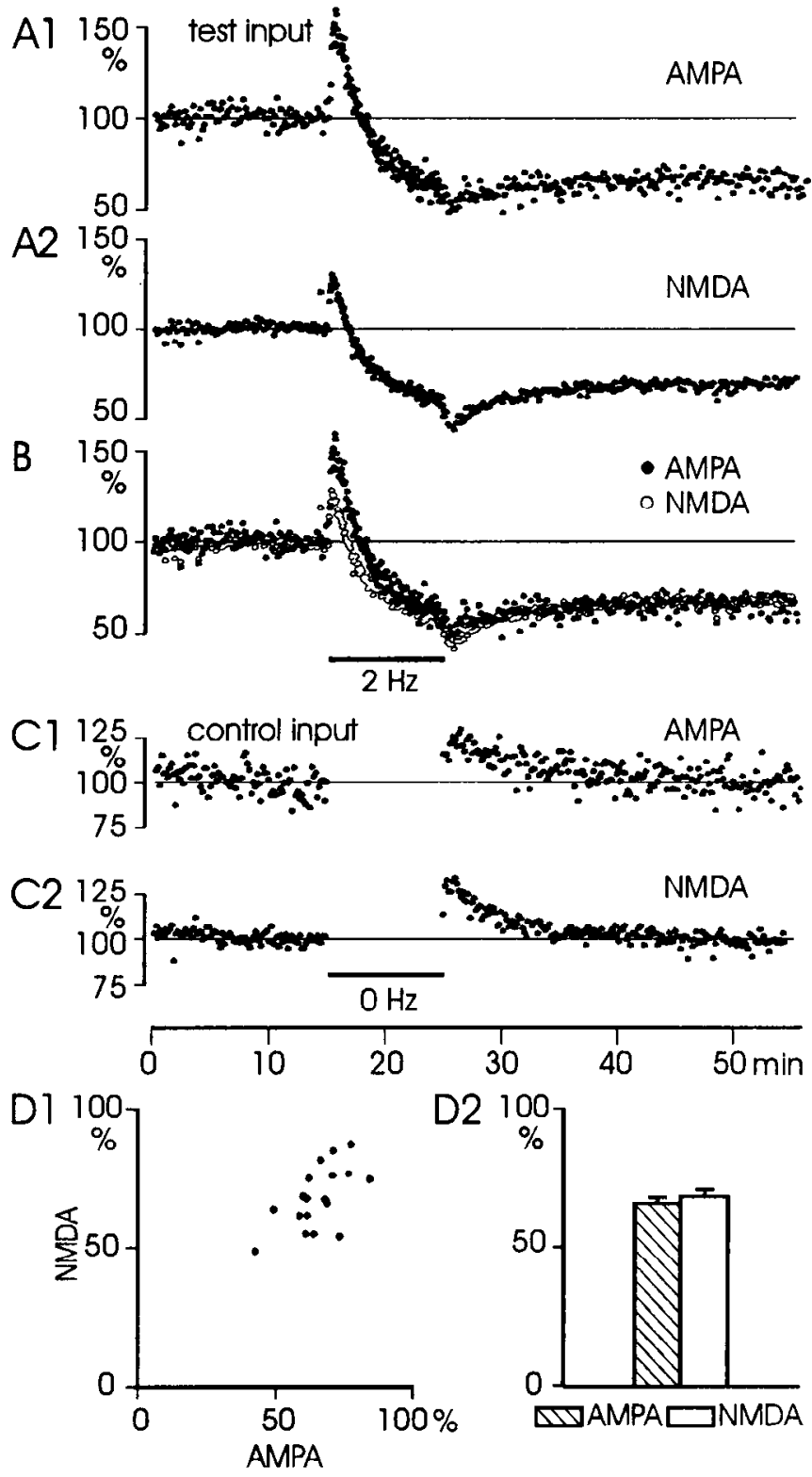

NMDA

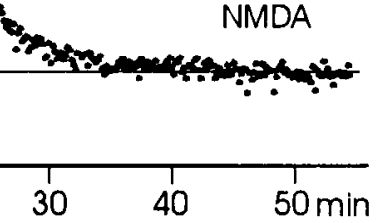

D2 100

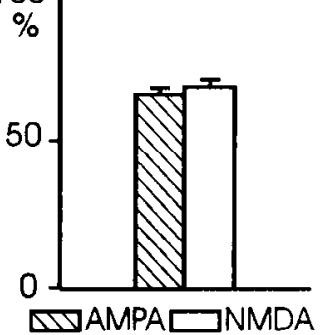

Figure 2. LTD is input specific and associated with an equal change of AMPA and NMDA receptor-mediated components of the field EPSP. $A$, Parallel measurements of AMPA $(A I)$ and NMDA $(A 2)$ receptormediated components of the field EPSP for a series of successive responses evoked by stimulating one of two independent synaptic pathways (test input) at a frequency of $0.1 \mathrm{~Hz}$. The values are plotted as averaged percentages of baseline values $(n=10$ experiments). LTD was induced by $10 \mathrm{~min}$ of $2 \mathrm{~Hz}$ stimulation using test stimulus strength (bar $2 \mathrm{~Hz}$; each fourth response is plotted during $2 \mathrm{I} z z$ stimulation). $B$, The measurements shown in $A l$ and $A 2$ are plotted superimposed with symbols as indicated. $C$, Plots of AMPA $(C l)$ and NMDA $(C 2)$ receptor-mediated components of the field EPSP of a separate synaptic pathway (control input). This input was silent during the 10 min of $2 \mathrm{H}$ \% stimulation of the test input (bar $\mathrm{OHz}$ ). DI, Relation between AMPA and NMDA receptor-mediated components for a set of 18 experiments (values taken 15-20 min after the induction of LTD). D2, values in $D I$, expressed as mean + SEM.

in an LTD of the AMPA receptor-mediated component (Fig. $2 A /$ ). After an initial 5-10 min decay, the depression was generally stable throughout the recording period of $30-60 \mathrm{~min}$. For the experiments illustrated in Figure $2 A l$, the AMPA receptor- 
mediated EPSP component, measured 15-20 min after the end of the LFS. was $63.4 \pm 2.9 \%(n=10)$ of the baseline value.

Figure $2 \mathrm{Cl}$ shows that no LTD occurred in the control pathway, indicating the input specificity of the effect. Control experiments (not illustrated) demonstrated that the transient increase that can be observed in the figure was related to our procedure of switching off the stimulation of the control input during LFS of the test input.

LTD of the NMDA receptor-mediated component. The NMDA receptor-mediated component of the composite field EPSP displayed an input specific LTD with a similar time course and magnitude as the I,TD of the AMPA receptor-mediated component (Fig. 2A2,C2). For the experiments illustrated in the figure the NMDA receptor-mediated component was $65.8 \pm$ $4.0 \%$ of the baseline value ( $n=10$ ) when measured $15-20 \mathrm{~min}$ after the LFS; that is, its depression was essentially the same as that of the AMPA receptor-mediated component. The similar magnitude and time course of the LTDs of the two EPSP components can also be appreciated in Figure $2 B$, where the two curves are shown superimposed.

For a somewhat larger sample $(n=18)$ the AMPA and NMDA receptor-mediated EPSP components were reduced to $65.6 \pm 2.4 \%$ and to $68.2 \pm 2.6 \%$ of the baseline value, respectively (Fig. 2D2). This average similarity in the LTDs of the two EPSP components was not just fortuitous. Figure $2 \mathrm{Dl}$, in which the LTDs of the AMPA and NMDA receptor-mediated EPSP components from each experiment are plotted against each other, indicates a significant covariation $(r=0.59, P<0.01)$.

\section{LTD of pure NMDA receptor-mediated EPSPs}

Since the LTD of the NMDA receptor-mediated EPSP described above was calculated from a late measurement only (see Materials and Methods), experiments were also carried out in a high CNQX concentration $(10 \mu \mathrm{M})$ that completely blocked the AMPA receptor-mediated component, leaving an isolated NMDA receptor-mediated EPSP. In Figure 3, $A$ and $B$ show that a standard LFS resulted in an input specific LTD of the pure NMDA receptor-mediated EPSP of similar time course and magnitude as the LTD of the NMDA receptor-mediated component seen in experiments using a composite EPSP. On the average the NMDA receptor-mediated EPSP (measured as the slope of the initial $5 \mathrm{msec}$ of the EPSP) was reduced to $57.4 \pm$ $3.7 \%$ of the baseline value $(n=6)$. This similarity in LTD of the NMDA receptor-mediated EPSP, when measured as initial slope or late on the falling phase of the EPSP, respectively, suggests that LTD is associated with a symmetrical change of the potential. Figure $3 C$, in which control and depressed NMDA receptor-mediated EPSPs are shown, illustrates that LTD is not associated with any change in the tine course of the field EPSP.

\section{LTD induction characteristics}

$N M D A$ receptor-dependent induction of $L T D$. In agreement with previous studies (Dudek and Bear, 1992; Mulkey and Malenka, 1992), LTD of the AMPA receptor-mediated component was not observed when the LFS was given in the presence of AP5 $(25-50 \mu \mathrm{M})$. In fact, as shown in Figure $4 C$, the LFS under this condition produced a slight increase of the AMPA receptormediated EPSP, to $107.1 \pm 4.8 \%$ of baseline value $(n=4)$.

AP5 was also found to prevent the induction of LTD of the NMDA receptor-mediated field EPSP (Fig. $4 E$ ). In this experiment, performed on a pure NMDA receptor-mediated EPSP, LFS applied in the presence of AP5 produced no LTD, as in-
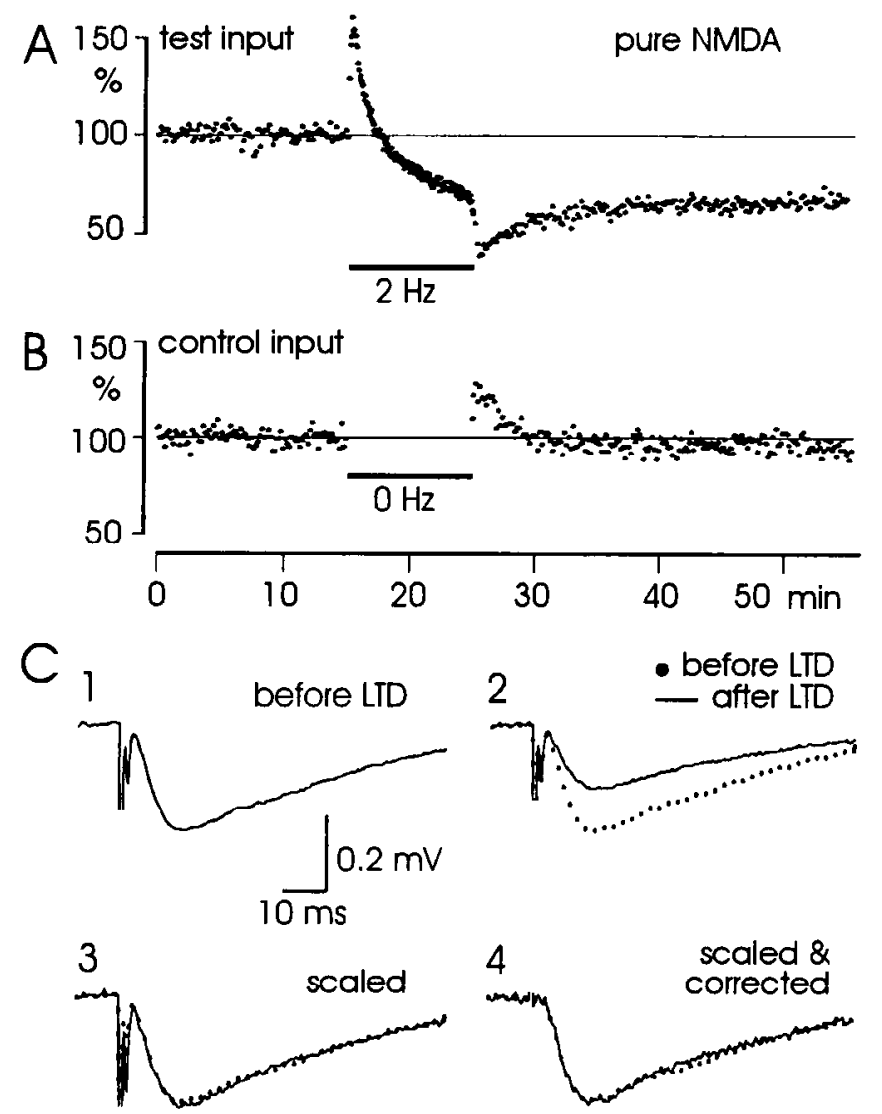

Figure 3. LTD of the isolated NMDA receptor mediated field EPSP is input specific and associated with a symmetric change of the potential. Experiments were carried out in the presence of $10 \mu \mathrm{M}$ CNQX to block completely the AMPA receptor-mediated component. $A$, Measurements of the slope (linear regression during the initial 5 msec) of the NMDA receptor-mediated field EPSP are plotted for a series of successive responses of the test input (stimulation trequency, 0.1 Hz). The values are plotted as averaged percentages of baseline values $(n=$ 6 experiments). LTD was induced by $10 \mathrm{~min}$ of $2 \mathrm{H} z$ stimulation using the test stimulus strength (bar $2 H z$ ). $B$, Same as in $A$, but for the control input which was silent during the $10 \mathrm{~min}$ stimulation of the test input (bar $0 \mathrm{~Hz}$ ). C. Averaged records of NMDA receptor-mediated field EPSPs from one of the experiments in $A$ are shown. $l$, control taken immediately before the $2 \mathrm{~Hz}$ stimulation; 2, during LTD (20 min after the end of $2 \mathrm{~Hz}$ stimulation) as a solid line together with the control EPSP (dotted); 3, same as 2, but the two curves are scaled to the same size; 4 , same as 3 , but both EPSPs have been corrected by subtracting the nonsynaptic potential obtained after drop application of AP5 (5) mM).

dicated by the return of the EPSP to baseline value after washout of AP5. Moreover, a subsequent LFS (after washout) produced a normal LTD. A similar result was found in two additional experiments using a pure NMDA receptor-mediated field EPSP, and in three experiments using a composite field EPSP.

On the other hand, AP5 did not affect the expression or maintenance of LTD (Fig. 4D). As shown in this figure, application of AP5 $1 \mathrm{hr}$ after the LFS only produced a slight further decrease of the AMPA receptor-mediated field EPSP measure (to 86.2 $\pm 4.0 \%$ of the value before AP5, $n=5$ ). This value is similar to that observed on a naive pathway (Materials and Methods) representing a slight contamination of this measure by the NMDA receptor-mediated component.

Other induction pathways in LTD? To further characterize the induction properties of LTD under the present experimental con- 
Figure 4. The induction of both AMPA and NMDA receptor-mediated LTD is NMDA receptor dependent, and it does not involve activation of either voltage-dependent calcium channcls or metabotropic glutamate receptors. Parallel measurements of AMPA and/or NMDA receptor-mediated components are plotted for a series of successive responses evoked at $0.1 \mathrm{~Hz}$. The values are plotted as averaged percentages of baseline values from several similar experiments $(A, n=4 ; B, n=4 ; C, n=$ 4 ), or as percentages of baseline values from single experiments $(D, E)$. LTD was induced by $10 \mathrm{~min}$ of $2 \mathrm{~Hz}$ stimulation (har $2 \mathrm{~Hz}$ ). A, Experiments were carried out with the L-type voltage-gated calcium channel blocker nifedipine $(20 \mu \mathrm{M})$ present in the bath. $B$. Experiments in the presence of the metabotropic glutamate receptor antagonist MCPG $(500 \mu \mathrm{M}) . C$, Experiments in the presence of the NMDA receptor antagonist AP5 $(25-50 \mu \mathrm{M})$. Under this condition only the AMPA receptormediated component could be observed. $D$. Single experiment in which AP5 $(25 \mu \mathrm{M})$ was applied in the bath about $1 \mathrm{hr}$ after the LTD induction, showing that AP5 had no effect on established LTD of the AMPA receptormediated component. $E$, Single cxperiment in which the NMDA receptormediated component was observed in isolation (in the presence of $10 \mu \mathrm{M}$ CNQX) showing that bath application of AP5 $(25 \mu \mathrm{M})$ blocked LTD induction. The subsequent washout of AP5 restored the capacity for LTD induction (second bar).

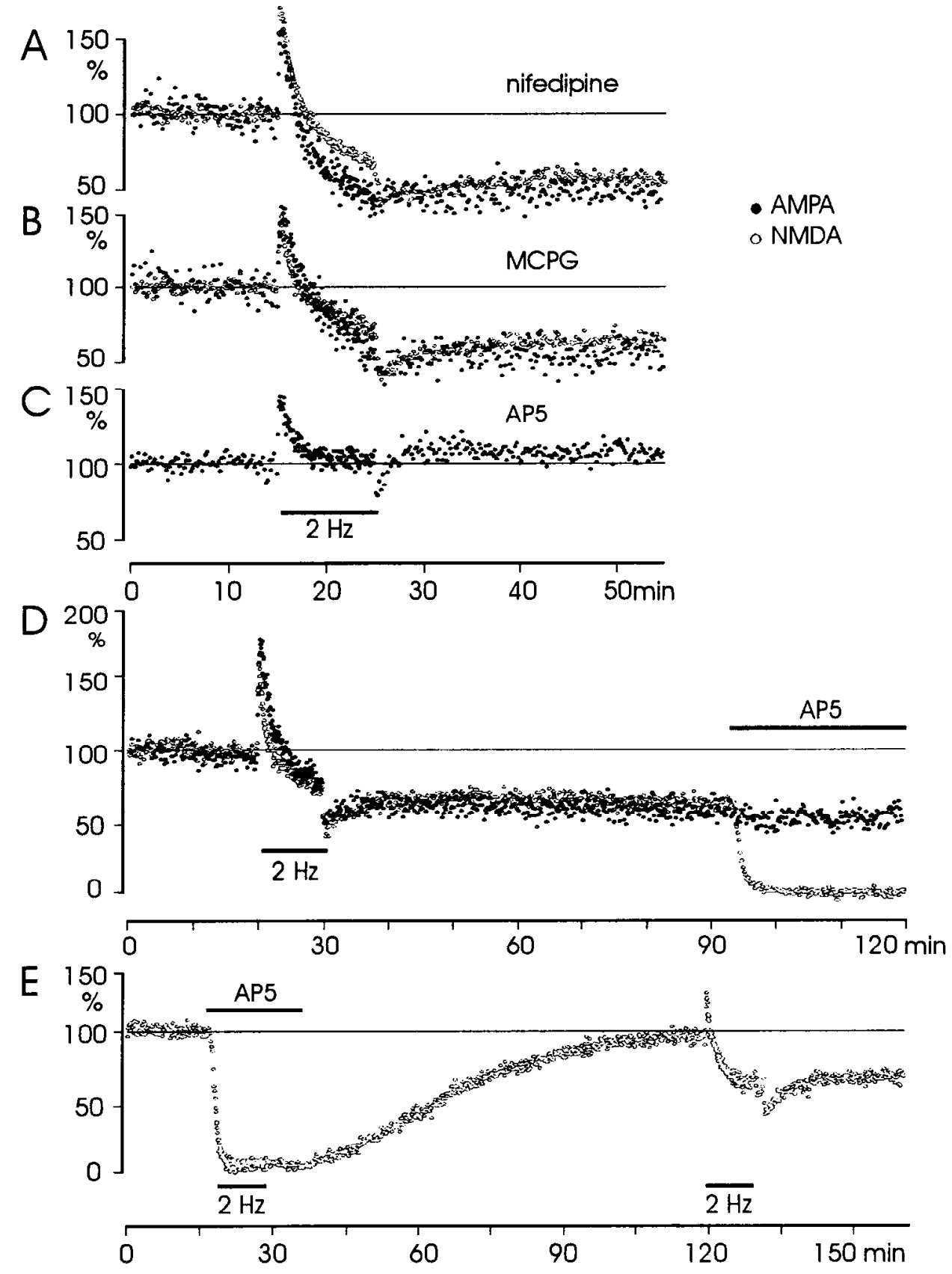

ditions, we examined whether the induction might involve activation of voltage-dependent calcium channels or of metabotropic glutamate receptors. LFS was applied to slices maintained in a solution containing nifedipine $(20 \mu \mathrm{M})$, a blocker of L-type voltage-gated calcium channels. The resulting LTD was even slightly greater under these conditions, the AMPA and NMDA receptor-mediated components decreasing to $49.4 \pm 6.6 \%$ and $53.8 \pm 4.3 \%$, respectively, of baseline values ( $n=4$; Fig. $4 A$ ). Similarly, in the presence of MCPG $(500 \mu \mathrm{M})$, an antagonist to the metabotropic glutamate receptor, the AMPA and NMDA receptor-mediated components decreased to $54.8 \pm 6.8 \%$ and $62.4 \pm 2.3 \%$, respectively, of baseline values $(n=4$; Fig. $4 B)$.

AMPA and NMDA receptor-mediated field EPSP changes in LTD-comparison with those induced by an adenosine agonist The near equal changes of AMPA and NMDA receptor-mediated components of the field EPSP observed during LTD might result from alterations in transmitter release. It therefore seemed of interest to compare the LTD-induced changes with those produced by an agent that is known to affect presynaptic function. In the experiments described below, the adenosine agonist $\mathrm{CHA}$, known to reduce the probability of transmitter release in hippocampal synapses (Burke and Nadler, 1988; Lupica et al., 1992; Prince and Stevens, 1992), was used. In most of the experiments, the drug was applied as a droplet of a relatively concentrated CHA solution $(200 \mu \mathrm{M})$ at some distance from the recording site. It was then allowed to equilibrate into the recording region until virtually no synaptic potential remained.

CHA-induced changes in AMPA and NMDA receptor-mediated field EPSPS. Figure 5 illustrates the experimental situation. One of the pathways (test input) was first tetanized by an LFS to induce LTD of the AMPA and NMDA receptor-mediated field EPSP components. CHA was applied about $30 \mathrm{~min}$ there- 

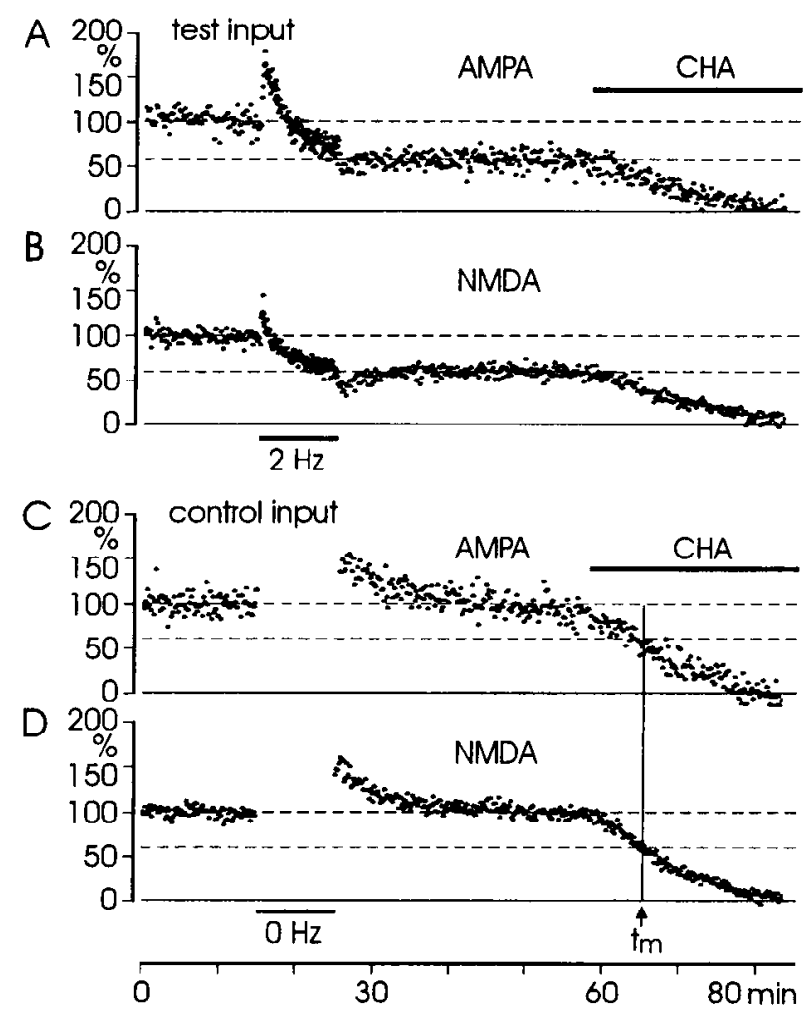

Figure 5. LTD and application of CHA affect AMPA and NMDA receptor-mediated components in a similar manner. Farallel measurements of AMPA and NMDA receptor-mediated components of the field EPSP are plotted for a series of successive responses in a single experiment. The two independent pathways (test and control inputs) were alternately stimulated at a frequency of $0.1 \mathrm{~Hz}$. Values are plotted as percentages of baseline values. A small drop of the adenosine agonist CHA $(200 \mu \mathrm{M})$ was applied as indicated, leading to a gradually developing blockade of the EPSP until no synaptic potential remained. For a comparison between LTD and the effect of CHA, the EPSP reduction during LTD in the test input and that induced by CHA in the control input were compared in the individual experiments at a similar magnitude. The mean of the percentage values of the AMPA and NMDA receptor-mediated components during LTD, relative to their baseline values, was determined in each experiment. Then, a time $t_{m}$ (indicated by a vertical line in $C$ and $D$ ) was determincd in cach experiment such that the mean of the percentage values of the AMPA and NMDA receptor-mediated components induced by $\mathrm{CHA}$ in the control input at $t_{m}$ was equal to the mean value (for LTD) mentioned above. The relative magnitudes of the AMPA and NMDA receptor-mediated responses at $t_{m}$ for the control input were then compared (1) with those obtained in the test input by the LFS alone and (2) with those in the test input at $t_{m}$.

after, affecting both the tetanized pathway and the naive control pathway. In the case illustrated in Figure 5, the LFS reduced both components to about $60 \%$ of baseline values (Fig. $5 A, B$ ). As indicated in Figure 5, $C$ and $D$, a CHA-induced reduction of the AMPA receptor-mediated component to $60 \%$ also corresponded to an approximate similar reduction in the NMDA receptor-mediated component. For 14 slices analyzed in this manner the AMPA and NMDA receptor-mediated components decreased during LTD, on average, to $58.1 \pm 2.8 \%$ and $63.0 \pm$ $3.0 \%$, respectively, of baseline values (see Fig. $7 A$ ). When comparing for similarly sized reductions induced by $\mathrm{CHA}$ in the control input (in each experiment; see Fig. 5 legend for a detailed description) the corresponding values were $60.8 \pm 2.7 \%$ and $60.3 \pm 2.4 \%$ of baseline values (see Fig. $7 \mathrm{~A}$ ).

The near equal changes in AMPA and NMDA receptor-me-

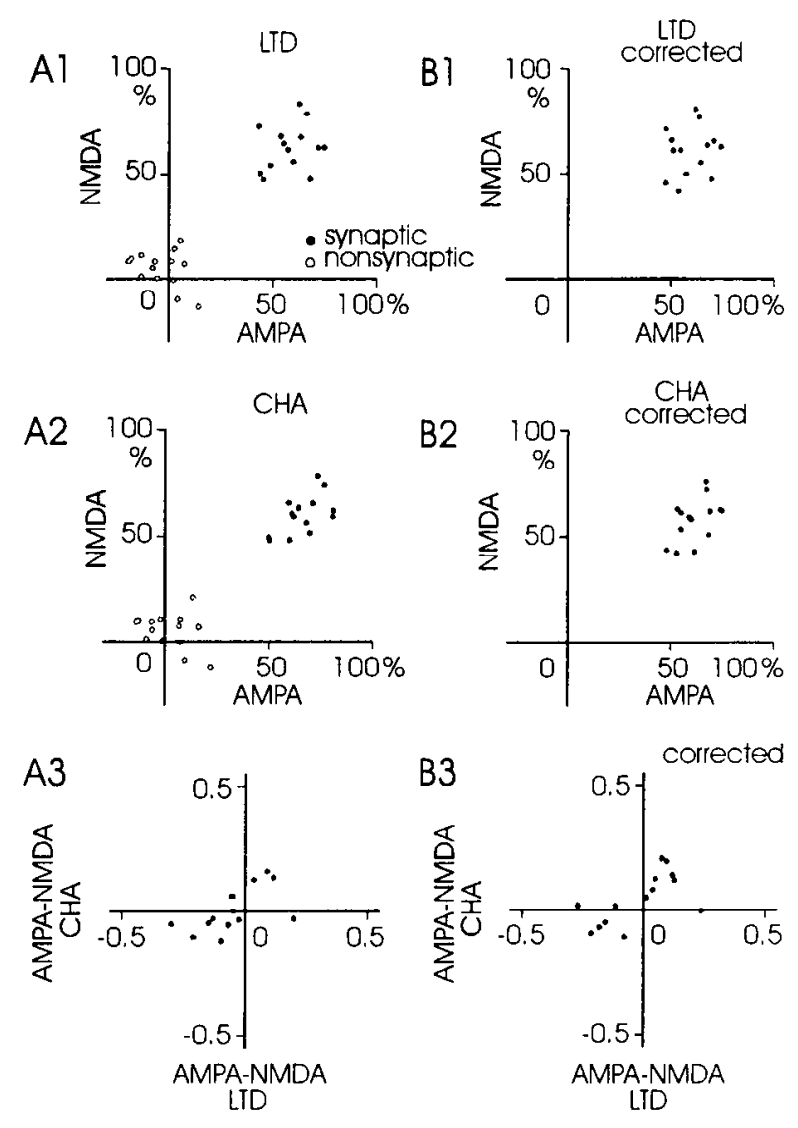

Figure 6. Comparison between LTD and CHA application. The relation between AMPA and NMDA receptor-mediated components (measured as percentages of baseline values) is shown for $\operatorname{LTD}(A / . B /)$ and for a similarly sized $\mathrm{CHA}$ effect $(A 2, B 2)$ determined as described in the Figure 5 legend. $A$ and $B$ are, respectively, before and after correction for nonsynaptic potentials. The corrected values were obtained by subtracting the nonsynaptic potential (in each slice/input) from the baseline EPSPs as well as from the EPSPs measured after LTD or CHA. $A 3$ and $B 3$, Relation between the deviations from equal changes in AMPA and NMDA receptor-mediated potentials in the depressions induced during LTD or by CHA application, before $(A)$ and after $(B)$ correction for nonsynaptic potentials.

diated EPSP components, described above, were independent of the particular manner in which the EPSP components were measured, both with respect to LTD and CHA. Figure $7 B$, in which field potentials averaged over the group of 14 slices used above are shown, illustrates that the composite field EPSP, after correction for the nonsynaptic potential, is essentially unaltered in its time course after LTD induction as well as after CHA application.

For the individual experiments, there was a considerable deviation with respect to equal changes in the LTDs of the AMPA and NMDA receptor-mediated components (Fig. 2D/). It thus seemed important to establish whether such deviations also occurred in connection with CHA application. Figure 6 shows the relation between the relative amounts of AMPA and NMDA receptor-mediated field EPSPs after LFS $(A l)$ and CHA $(A 2)$, respectively, for the experiments described above. The graphs indicate a considerable deviation from equal AMPA and NMDA receptor-mediated field EPSP changes, both with respect to LTD and CHA. A possible cause for these deviations could be interference from the presynaptic volley and stimulus artifact, that is, from the nonsynaptic potential (Materials and Methods). To 


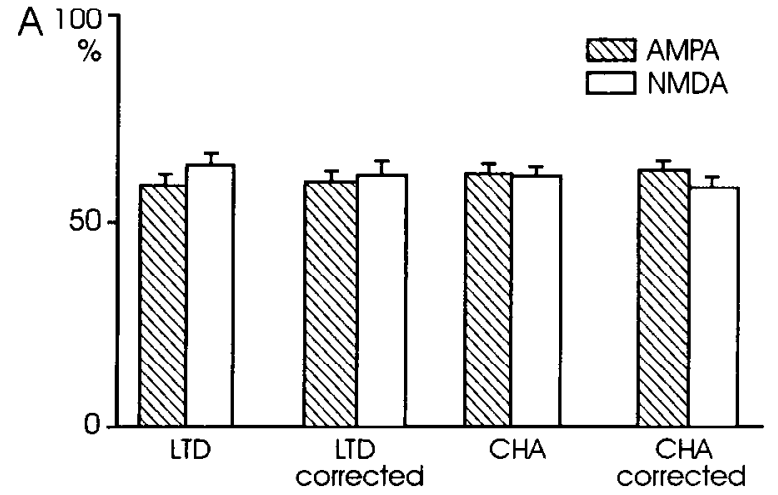

B

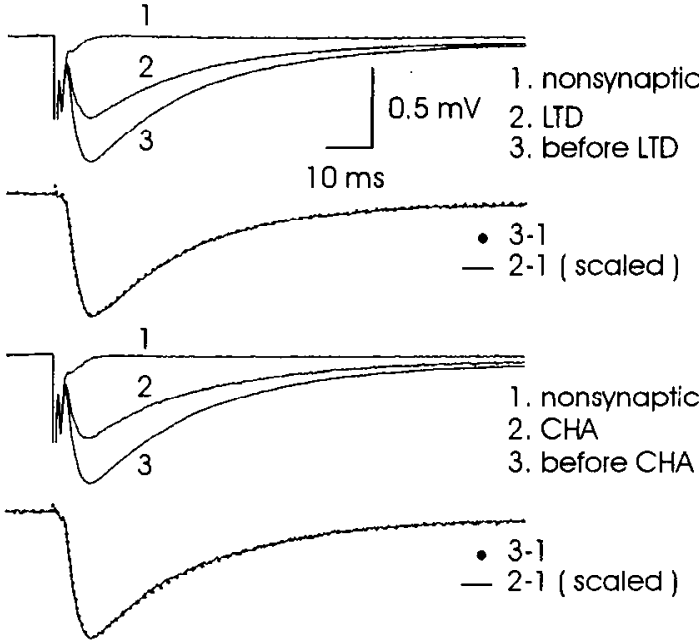

Figure 7. Comparison between LTD and CHA application: average results. $A$, Reductions in AMPA and NMDA receptor-mediated components for LTD and for similarly sized CHA elfects (see Fig. 5 legend), before and after correction for nonsynaptic potentials (mean + SEM for the data in Fig. $6 ; n=14) . B$, Averages of average potentials recorded in the 14 experiments, for LTD (test input; upper records) and for CHA (control input: lower records). The potentials used for CHA were matched in size to those subjected to LTD according to the method described in the Figure 5 legend. 1 , after complete blockade of synaptic transmission by CHA (nonsynaptic potential); 2, after LTD or CHA application; 3 , haseline FPSP. It can be noted that the depression occurred without changes in the shape of the composite EPSP (both for LTD and CHA) as evidenced by the close match between the scaled EPSPs (solid) and the baseline EPSPs (dotted).

examine this possibility the potential remaining after complete blockade of transmitter release by drop application of CHA (200 $\mu \mathrm{M})$ was used as nonsynaptic potential. As indicated by the open circles in Figure 6, representing the initial slope and late amplitude measurements applied to the nonsynaptic potcntial, the measurements of AMPA and NMDA receptor-mediated field EPSPs were contaminated by nonsynaptic effects. However, as shown in Figure $6 B$, in which the data points in Figure $6 A$ are replotted after correction by their corresponding nonsynaptic values, the correction for nonsynaptic.effects did not improve the correlation for the individual experiments (Fig. 6BI,B2). On the other hand, the average reduction in AMPA and NMDA receptor-mediated field EPSPs by $L F S$ and $C H A$ remained approximately the same as before (Fig. $7 A$ ).

The results presented in Figure 6 thus suggest that considerable deviations from equal changes in AMPA and NMDA receptor-mediated field potentials can occur, both following LFS and CHA application. These deviations were, however, corre-
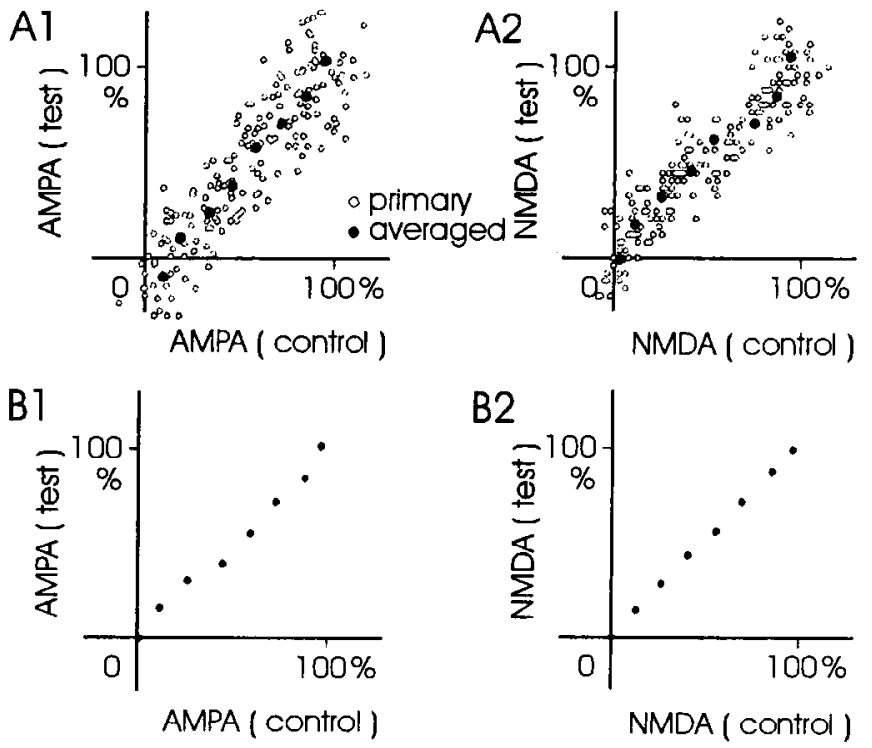

Figure 8. LTD and CHA interact in a multiplicative manner. Al, Relation between the AMPA receptor-mediated components of the test (subjected to LTD) and control (naive) inputs during the progressive action of $\mathrm{CHA}$, as percentage of baseline values before $\mathrm{CHA}$ application. A2, Similar to $A 1$, but shows the relation between the NMDA receptor-mediated components of the two inputs. The original measurements are shown as open circles, whereas averages of binned data are indicated by larger, solid circles. $B I$ and $B 2$, averages of AMPAAMPA and NMDA-NMDA relations (see above) for a set of 14 experiments.

lated with each other such that in experiments in which LFS gave a larger change in the AMPA receptor-mediated component than in the NMDA receptor-mediated one, or vice versa, the same tended to be true for CHA application. This result is illustrated in Figure 6, $A 3$ and $B 3$.

Interaction between $L T D$ and the synaptic depression given by CHA. As illustrated in Figure 5, the effect of CHA application was tested both for a naive pathway (control input) and for one that had been subjected to LTD (test input). To examine how CHA affected these two inputs, the magnitudes of the AMPA, and NMDA, receptor-mediated components (relative to baseline values before drug application) obtained during the progressive action of $\mathrm{CHA}$ for each of the two inputs were plotted against each other. Figure $8 A$, showing values from a single experiment, indicates that the EPSPs from the two inputs changed in a proportional manner (solid circles represent average of binned data). The data pooled from all 14 experiments (Fig. $8 B$ ) demonstrate that both the AMPA and NMDA receptor-mediated EPSPs were affected in an equal manner for the two inputs, for the whole range of partially blocked EPSPs. The EPSP depression induced by $\mathrm{CHA}$ thus interacts in a multiplicative manner with that appearing during LTD, indicating that these two processes are mechanistically independent.

Induction of $L T D$ in the presence of $C H A$. In agreement with the above independence, normal amounts of LTD were also evoked in the presence of an EPSP depression induced by $\mathrm{CHA}$. A constant concentration of C.HA (100 nM) was applied in the perfusion solution, leading to a decrease of the EPSP to about $20-30 \%$ of its original magnitude. LTD induced under those conditions was similar to that seen in the standard solution, the AMPA and NMDA receptor-mediated components changing to 


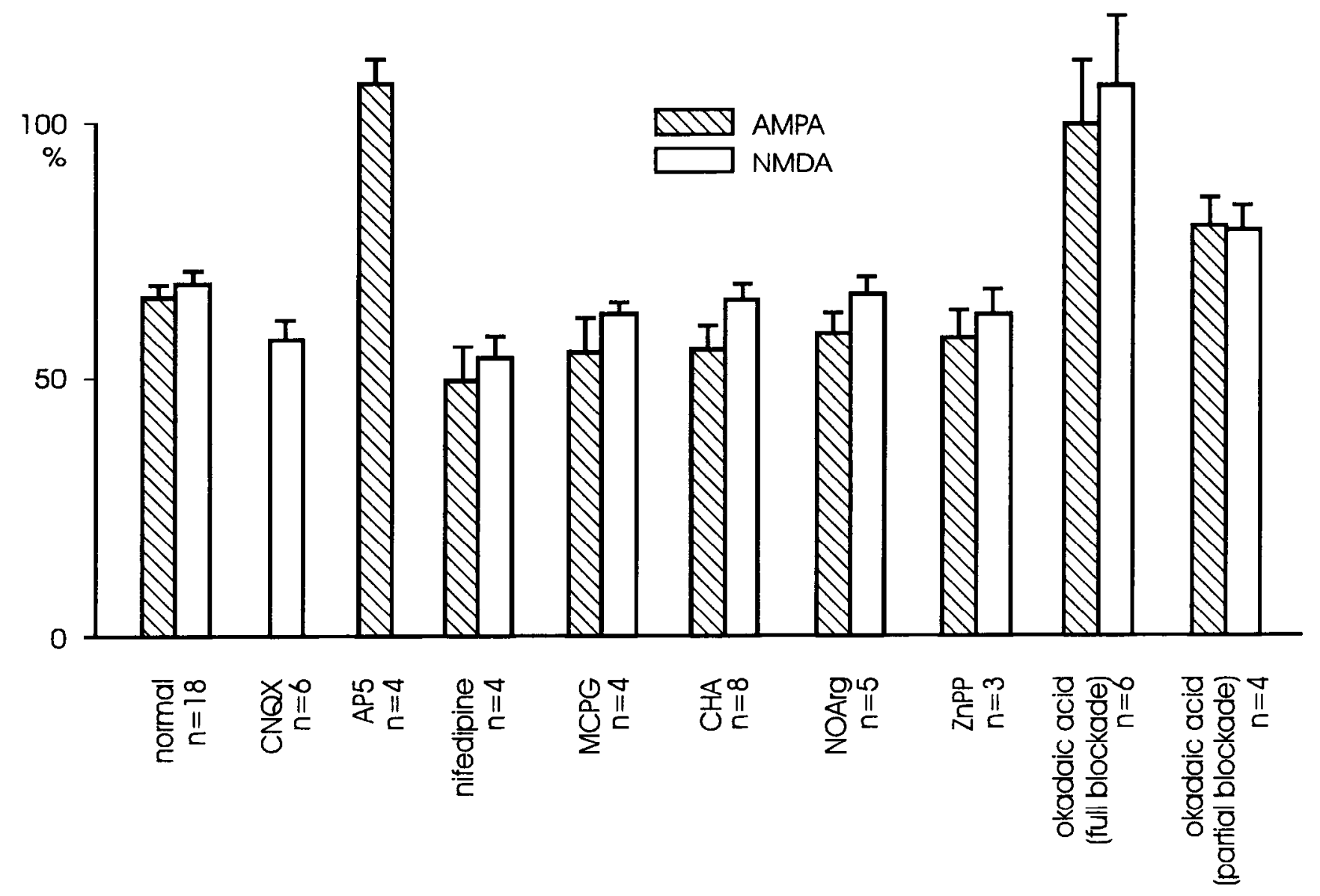

Figure 9. Summary of relation between AMPA and NMDA receptor-mediated components during LTD under various conditions. Bars represent the magnitudes of AMPA and NMDA receptor-mediated components of the field EPSP (15-20 min after LTD induction) as percentage of baseline values, in experiments performed in normal perfusion solution and in the presence of different drugs: CNQX (pure NMDA receptor-mediated EPSP), AP5 (pure AMPA receptor-mediated EPSP), nifedipine, MCPG, CHA. NOArg. ZnPP, and okadaic acid (full and partial blockade). The error bars are SEM.

$55.4+4.6 \%$ and $65.1 \pm 2.9 \%$, respectively, of baseline values $(n=8)$.

\section{LTD and paired-pulse facilitation}

Alterations in the degree of paired-pulse facilitation are often used to test for an involvement of a presynaptic change (McNaughton, 1982; Manabe et al., 1993). However, measuring paired-pulse facilitation in the present experimental situation was complicated by the long duration of the NMDA receptormediated EPSP, this EPSP tending to interfere with the second response of a pair. Paired-pulse tests (using a $30-50 \mathrm{msec}$ interstimulus interval) were therefore carried out on pure AMPA receptor-mediated EPSPs obtained while blocking the NMDA receptor-mediated conponent by AP5 $(50 \mu \mathrm{M})$. Thus, after baseline values of paired-pulse facilitation had been recorded, AP5 was washed out, LTD was induced, and AP5 was again applied to allow for a second period of paired-pulse recording. In these experiments, LTD (to $63.4 \pm 5.0 \%$ of the baseline value) produced no significant change in paired-pulse facilitation; the magnitude of the second response, relative to the first one, was 168.4 $\pm 8.0 \%$ and $176.1 \pm 11.6 \%(n=7, p>0.05)$, respectively, before and after LTD had been induced.
Involvement of retrograde messengers?

Since LTD is considered to be induced postsynaptically (Dudek and Bear, 1992, 1993; Mulkey and Malenka, 1992), a presynaptic location for its expression would necessitate a retrograde messenger, such as nitric oxide (NO) or carbon monoxide (CO) (Hawkins et al., 1994; Schuman and Madison, 1994). In order to test for such involvement, LFS was given in the presence of the nitric oxide synthase inhibitor Nw-nitro-L-arginine (NOArg; $100 \mu \mathrm{M})$ or the heme oxygenase inhibitor protoporphyrin IX zinc(II) $(7 . \mathrm{nPP} ; 10 \mu \mathrm{M})$. ITD induced in the presence of either of these drugs did not differ significantly from the LTD seen under control conditions, the AMPA and NMDA receptor-mediated components being reduced to $58.5 \pm 4.1 \%$ and $66.1 \pm$ $3.5 \%$, respectively, of baseline values in the NOArg experiments $(n=5)$ and to $57.7 \pm 5.4 \%$ and $62.3 \pm 4.7 \%$ in the $\mathrm{ZnPP}$ experiments $(n=3$ ) (Fig. 9).

\section{Protein phosphatases and LTD}

Application of phosphatase inhibitors has previously been shown to block the LTD of the AMPA receptor-mediated field EPSP (Mulkey et al., 1993, 1994). In the present study, incubation of the slices in okadaic acid $(1 \mu \mathrm{M})$ for several hours resulted in a total blockade of LTD not only of the AMPA receptor-mediated 
component, but also of the NMDA receptor-mediated one (Fig. 9). To examine whether okadaic acid might differentially influence LTD of the two EPSP components, an LFS was also given in slices treated with okadaic acid for shorter times than those used above, leading to a partial blockade of LTD. On average. the AMPA and NMDA receptor-mediated components were affected to a similar extent, being reduced to $79.1 \pm 5.8 \%$ and $78.6 \pm 4.9 \%$, respectively, of baseline values $(n=4$; Fig. 9).

\section{Discussion}

The present study suggests that the homosynaptic LTD observed after low-frequency activation in the hippocampal CAI region is associated with near equal depression of the AMPA and NMDA receptor-mediated components of the field EPSP. This parallel depression was found to be a robust phenomenon that resisted a number of different pharmacological manipulations, a result indicating a common induction, as well as a common locus of expression, for the LTDs of the AMPA and NMDA receptor-mediated EPSPs. Application of an adenosine agonist that depresses EPSPs via a reduction in presynaptic transmitter release (Burke and Nadler, 1988; Lupica et al., 1992; Prince and Stevens, 1992) produced a depression of the AMPA and NMDA receptor-mediated components of the field EPSP that resembled that which occurred during LTD. On the other hand, the field EPSP depressions induced by low-frequency activation and an adenosine agonist, respectively, did not interact with each other. Nor was paired-pulse facilitation significantly affected by LTD. The present results, then, seem to favor the idea that LTD expression has a presynaptic locus, but with a mechanism of undefined nature.

\section{Identity of the studied LTD}

In contrast to previous studies on homosynaptic NMDA receptor-dependent LTD induced by prolonged (5-10 $\mathrm{min}$ ) low-frequency (1-2 Hz) activation (Dudek and Bear, 1992; Mulkey and Malenka, 1992), the present study was performed using a lowmagnesium solution (boosting the NMDA receptor-mediated EPSP) and with partial blockade of the AMPA receptor-mediated EPSP. Nevertheless, the LTD of the AMPA receptor-mediated LTD observed under our experimental conditions had a similar magnitude and time course as that observed previously examining AMPA receptor-mediated EPSPs in isolation (for references, see above). Furthermore, in agreement with this latter LTD. the presently observed one was input specific, and it was blocked by an NMDA receptor antagonist and by a phosphatase inhibitor. Finally, it was predominantly found in young (2-3week-old) rats, being substantially less in older ones (unpublished observations). There is thus no obvious reason to consider this LTD to be a separate phenomenon from the homosynaptic LTD previously described.

A homosynaptic LTD of the (isolated) NMDA receptor-mediated EPSP has also previously been described in the CA1 region (Gean and Lin, 1993). This LTD of the NMDA receptormediated EPSP was evoked by prolonged low-frequency afferent activation, but only when it was paired with postsynaptic membrane depolarization, indicating to the authors a higher threshold for induction than for the LTD of the AMPA receptormediated EPSP. However, since the LTD observed by Gean and Lin (1993) had a similar time course and magnitude as that observed here, and since it was also blocked by an NMDA receptor antagonist, it likely represents the same LTD as that observed here. If so, the alleged difference in induction threshold between the LTDs of the AMPA and NMDA receptor - mediated EPSPs may be more apparent than real.

\section{Validity of the EPSP measurements}

The parallel measurement of AMPA and NMDA receptor-mediated EPSPs used in the present study necessitated the use of a composite field EPSP in which the two EPSP components were extracted by measuring at specific times after stimulus onset. The AMPA receptor-mediated component was thus estimated from an initial slope measurement, and the NMDA receptor-mediated one from a late measurement (Materials and Methods). A matter of concern is then to what extent these measures have given an accurate representation of changes in the two EPSP components. As shown, the initial slope measurement contained a small fraction that was NMDA receptor mediated since the initial slope was reduced by about $15 \%$ following application of AP5. However, if, as indicated in this study, the NMDA receptor-mediated component changes in much the same manner as the AMPA receptor-mediated one, no correction for this overlap should be needed. What is then more of a concern is whether the late amplitude measurement accurately reflects changes in the NMDA receptor-mediated EPSP. This measurement may be affected not only by the magnitude of the AMPA receptor-mediated EPSP, due to the voltage dependence of the NMDA receptor channels still remaining in $0.1 \mathrm{~mm}$ magnesium, but also by the magnitude of $\mathrm{GABA}$ receptor-mediated inhibition. However, as mentioned in Materials and Methods, the late measurement can most likely be seen as a valid measure of the NMDA receptor-mediated EPSP. In brief, a field EPSP recorded at a range of stimulus strengths showed a parallel increase in initial slope and late amplitude measurements. Moreover, a complete block of the AMPA receptor-mediated EPSP did not affect the late measurement, indicating little influence from membrane voltage and inhibition. Finally, when inducing LTD on an isolated NMDA receptor-mediated field EPSP, the EPSP shape was unaltered, suggesting that changes in the late measurement accurately described that of the potential as a whole.

Nonetheless, the EPSP measurements were affected by the. so-called, nonsynaptic potential, representing stimulus artifact and presynaptic volley (Figs. 6, 7B; see also Materials and Methods). When calculated for a hypothetical case in which the average nonsynaptic potential was added to an ideal composite field EPSP that was uniformly depressed, the depression of the AMPA and NMDA receptor-mediated EPSPS should differ by about 3-5\% (AMPA more depressed). This result may then explain the small, but rather consistent, difference in LTD of the two EPSP components that can be observed in our material.

\section{Common induction of LTD of AMPA and NMDA receptor- mediated EPSPS}

Induction of LTD of AMPA and NMDA receptor-mediated EPSPs does not necessarily have to be the same. For instance, with respect to LTP, metabotropic glutamate receptor activation has been reported to have a differential role for AMPA and NMDA receptor-mediated EPSPs (O'Connor et al., 1994). No evidence for such different induction requirements was found in the present study. The induction of LTD of both $\triangle M P A$ and NMDA receptor-mediated EPSPs was blocked by an NMDA receptor antagonist, and in neither case was the induction affected by block of L-type voltage-gated calcium channels or of the metabotropic glutamate receptor. This latter result also in- 
dicates that the LTD presently observed differs from that recently described in neonatal (3-7 d) rats, an LTD that was found to depend on both voltage-gated calcium channels and metabotropic glutamate receptor activation for its induction (Bolshakov and Siegelbaum, 1994).

This apparent similarity in induction was also found to extend to the possible enzymatic systems triggered by the NMDA receptor activation. As shown previously, LTD of the AMPA receptor-mediated EPSP is blocked in the presence of phosphatase inhibitors (Mulkey et al., 1993, 1994), and the present study showed that this was also the case for LTD of the NMDA receptor-mediated EPSP. More importantly, a brief exposure to a phosphatase inhibitor, leading to a partial blockade of the LTD of the AMPA receptor-mediated EPSP, led to a similar partial blockade of the LTD of the NMDA receptor-mediated EPSP, indicating a close coupling between the two LTDs.

Whereas some studics have implicated NO or $\mathrm{CO}$ as retrograde messengers in LTD (see Hawkins et al., 1994; Schuman and Madison, 1994), other studies have not substantiated this notion (Cummings et al., 1994). In our hands, inhibitors of NO and CO syntheses had no effect on LTD of either the AMPA or NMDA receptor-mediated EPSP. Besides demonstrating a further shared property for the LTDs of the two EPSP components, this result also suggests that to the extent that LTD expression is presynaptic, LTD makes use of a retrograde signaling pathway that does not involve $\mathrm{NO}$ or $\mathrm{CO}$.

\section{Implications for the locus of LTD expression}

An important aim for the present study was to find out how the LTD-associated changes in AMPA and NMDA receptor-mediated EPSPs compared with those produced by some agent that affected presynaptic function. The present results indicate a good agreement. As was the case for LTD, application of the adeno sine agonist CHA gave, on average, an equal depression of the two measures used for the estimation of the two EPSP components. When examined for individual experiments, deviations from equal change in AMPA and NMDA receptor-mediated EPSPs were observed in association with LTD as well as after CHA application. These deviations, whatever their origin, were clearly correlated such that if LTD produced a larger change in the measurement of the AMPA than in that of the NMDA receptor-mediated component, this tended also to be the case after CHA application. The present results are then clearly compatible with an LTD based on a decrease in presynaptic release probability. They would also support the notion that the increased number of failures observed after LTD induction (Stevens and Wang, 1994) corresponds to a presynaptic failure rather than to a postsynaptic modification, unless the latter one consists of a coordinated dropout of both AMPA and NMDA receptor channels. One would then have to surmise that the phosphatase involved in LTD (Mulkey et al., 1993) either is a postsynaptic one, taking part in the production of a retrograde messenger, or is a presynaptic one.

According to another scenario, LTP/LTD is seen as a postsynaptic interaction of kinase/phosphatase actions on the AMPA receptor channels (Lisman and Goldring, 1988; Lisman, 1989, 1994, Mulkey et al., 1993; Bear and Malenka, 1994). The present results would then suggest that this postsynaptic enzyme action must act in parallel on both AMPA and NMDA receptor channels. Whereas such a postsynaptic scenario may be less attractive, considering the rather close linkage between the LTDs of the AMPA and NMDA receptor-mediated EPSPs discussed above, it may easier explain the clearly unequal changes in AMPA and NMDA receptor-mediated EPSPs seen during LTP (Muller and Lynch, 1988; Asztely et al., 1992; Perkel and Nicoll, 1993). One may then envisage that the AMPA and NMDA receptor channels are phosphorylated at different rates but dephosphorylated at equal rates, and thus would be differentially affected with respect to LTP and LTD.

\section{LTD_does it interact with changes in presynaptic function.'}

A common argument against a presynaptic locus for LTP expression is that LTP does not seem to interact with other changes in presynaptic function. Thus, it has been reported that pairedpulse facilitation is unaffected by LTP (McNaughton, 1982; Gustafsson et al., 1988; Manabe et al., 1993; but see Schulz et al., 1994) and that changes in release induced by alteration of the calcium/magnesium relation or by adenosine agonists/antagonists affect naive and tetanized inputs equally (Huang et al., 1987, 1988; Muller and Lynch, 1989; Asttely et al., 1994). A lack of interaction between LTD and paired-pulse facilitation has previously been observed in normal solution (Mulkey and Malenka, 1992) and was also observed presently in our situation with a likely higher basal release due to low-magnesium concentration. In addition, the relative degree of EPSP reduction by CHA application was equal for naive pathways and pathways subjected to LTD, and equal amounts of LTD were obtained before and after CIIA application. An LTD based on a change in transmitter release must then be well separated from other such mechanisms.

\section{Concluding remarks}

The present study demonstrates that homosynaptic NMDA-dependent LTD is associated with near equal changes in AMPA and NMDA receptor-mediated EPSPs, a characteristic that appeared to resist all biochemical and pharmacological manipulalions used in this study. A possible mechanism for this belavior is a coordinated dropout of both AMPA and NMDA receptor channels in the postsynaptic membrane. A more straightforward explanation of these results is that LTD is due to a decrease in transmitter release. However, such a conclusion should be tempered by the lack of interaction between LTD and synaptic release changes produced by paired-pulse facilitation and an adenosine agonist.

\section{References}

Artola A, Singer W (1993) Long-term depression of excitatory synaptic transmission and its relationship to long-term potentiation. Trends Neurosci 16:480-487.

Asztely F, Wigström H, Gustafsson B (1992) The relative contribution of NMDA receptor channels in the expression of long-term potentialtion in the hippocampal CA1 region. Eur J Neurosci 4:681-690.

Asztely F, Xiao M-Y, Wigström H, Gustafsson B (1994) Effect of adenosine-induced changes in presynaptic relcase probability on long-term potentiation in the hippocampal CAl region. J Neurosci 14:67076714.

Bear MF, Malenka RC (1994) Synaptic plasticity: LTP and LTD. Curr Opin Neurobiol 4:389-399.

Bliss TVP, Collingridge GL (1993) A synaptic model of memory: longterm potentiation in the hippocampus. Nature 361:31-39.

Bolshakov VY, Siegelbaum SA (1994) Postsynaptic induction and presynaptic expression of hippocampal long-term depression. Science 264:1148-1152.

Burke SP, Nadler JV (1988) Regulation of glutamate and aspartate release from slices of the hippocampal CAI area: effects of adenosine and baclofen. J Neurochem 51:1541-1551.

Clark KA, Collingridge GL (1994) Long-term potentiation of AMPA 
and NMDA receptor-mediated synaptic transmission in hippocampal slices. J Physiol 476:69P-70P.

Collingridge GL, Herron CE, Lester RA (1988) Synaptic activation of $N$-methyl-D-aspartate receptors in the Schaffer collateral-commissural pathway of rat hippocampus. J Physiol (Lond) 399:283-300.

Cummings JA, Nicola SM, Malenka RC (1994) Induction in the rat hippocampus of long-term potentiation (LIP) and long-term depression (LTD) in the presence of a nitric oxide synthase inhibitor. Neurosci Lett 176:110-114.

Dudek SM, Bear MF (1992) Homosynaptic long-term depression in area CAl of hippocampus and effects of $N$-methyl-D-aspartate receptor hlockade. Proc Natl Acad Sci USA 89:4363-4367.

Dudek SM, Bear MF (1993) Bidirectional long-term modification of synaptic effectiveness in the adult and immature hippocampus. J Neurosei $13: 2910-2918$

Gean PW, Lin JH (1993) D-2-Amino-5-phosphonovalerate blocks induction of long-term depression of the NMDA receptor-mediated synaptic component in rat hippocampus. Neurosci Lett 158:170-172.

Gustafsson B, Huang Y-Y, Wigström H (1988) Phorbol ester-induced synaptic potentiation differs from long-term potentiation in the guinea pig hippocampus in vitro. Neurosci Lett 85:77-80.

Hawkins RD, Zhuo M, Arancio O (1994) Nitric oxide and carbon monoxide as possible retrograde messengers in hippocampal longterm potentiation. J Neurobiol 25:652-665.

Hestrin S, Nicoll RA, Perkel DJ, Sah P (1990) Analysis of excitatory synaptic action in pyramidal cells using whole-cell recording from rat hippocampal slices. J Physiol (Lond) 422:203-225.

Huang Y-Y, Wigström H, Gustafsson B (1987) Facilitated induction of hippocampal long-tem potentiation in slices perfused with low concentrations of magnesium. Neuroscience 22:9-16.

Huang Y-Y, Gustafsson B, Wigström H (1988) Facilitation of hippocampal long-term potentiation in slices perfused with high concentrations of calcium. Brain Res 456:88-94.

Kauer JA, Malenka RC, Nicoll RA (1988) A persistent postsynaptic modification mediates long-term potentiation in the hippocampus. Neuron 1:911-917.

Linden DJ (1994) Long-term synaptic depression in the mammalian brain. Neuron 12:457-472.

Lisman JE (1989) A mechanism for the Hebb and the anti-Hebb processes underlying learning and memory. Proc Natl Acad Sci USA $86: 9574-9578$.

Lisman JE (1994) The CaM kinase II hypothesis for the storage of synaptic memory. Trends Neurosci 17:406-412.

Lisman JE, Goldring MA (1988) Feasibility of long-term storage of graded information by the $\mathrm{Ca}^{++} / \mathrm{Calmodulin-dependent} \mathrm{protein} \mathrm{kinase}$ molecules of the postsynaptic density. Proc Natl Acad Sci USA 85: $5320-5324$.

Lupica CR. Proctor WR, Dunwiddie TV (1992) Presynaptic inhibition of excitatory synaptic transmission by adenosine in rat hippocampus: analysis of unitary EPSP variance measured by whole-cell recording. J Neurosci 12:3753-3764.

Manabe T, Wyllie DJ, Perkel DJ, Nicoll RA (199.3) Modulation of synaptic transmission and long-term potentiation: effects on paired pulse facilitation and EPSC variance in the CAl region of the hippocampus. J Neurophysiol 70:1451-1459.

McNaughton BL (1982) Long-term synaptic enhancement and shortterm potentiation in rat fascia dentata act through different mechanisms. J Physiol (Lond) 324:249-262.

Mulkey RM, Malenka RC (1992) Mechanisms underlying induction of homosynaptic long-term depression in area CAI of the hippocampus. Neuron 9:967-975.

Mulkey RM, Herron CE, Malenka RC (1993) An essential role for protein phosphatases in hippocampal long-term depression. Science 261: 1051-1055.

Mulkey RM, Endo S, Shenolikar S, Malenka RC (1994) Involvement of a calcineurin/inhibitor-1 phosphatase cascade in hippocampal longterm depression. Nature 369:486-488.

Muller D, Lynch G (1988) Long-term potentiation differentially affects Iwo components of synaptic responses in hippocampus. Proc Natl Acad Sci USA 85:9346-9350

Muller D, Lynch G (1989) Evidence that changes in presynaptic calcium currents are not responsible for long-term potentiation in the hippocampus. Brain Res 479:290-299.

O'Connor JJ, Rowan MJ, Anwyl R (1994) Long-lasting enhancement of NMDA receptor-mediated synaptic transmission by metabotropic glutamate receptor activation. Nature 367:557-559.

Perkel DJ. Nicoll RA (1993) Evidence for all-or-none regulation of neurotransmitter release: implications for long-term potentiation. J Physiol (Lond) 471:481-500.

Prince DA, Stevens CF (1992) Adenosine decreases neurotransmitter release at central synapses. Proc Natl Acad Sci USA 89:8586-8590.

Schulz PE, Cook EP, Johnston D (1994) Changes in paired-pulse facilitation suggest presynaptic involvement in long-term potentiation. J Neurosci 14:5325-5337.

Schuman EM, Madison DV ( 1994) Nitric oxide and synaptic function. Annu Rev Neurosci 17:153-183.

Stevens CF, Wang Y (1994) Changes in reliability of synaptic function as a mechanism for plasticity. Nature 371:704-707.

Wigström H, Gustafsson B (1985) On long-lasting potentiation in the hippocampus: a proposed mechanism for its dependence on coincident pre- and postsynaptic activity. Acta Physiol Scand 123:519-522.

Wigström H, Gustafsson B (1986) Postsynaptic control of hippocampal long-term potentiation. J Physiol (Paris) 81:228-236.

Xiao M-Y, Wigström H, Gustafsson B (1994) Long-term depression in the hippocampal CAl region is associated with equal changes in AMPA and NMDA receptor-mediated synaptic potentials. Eur J Neurosci $6: 1055-1057$. 